\title{
AC 2009-734: INTEGRATING PROFESSIONAL TOPICS AND ENGINEERING CONSTRAINTS ACROSS THE CURRICULUM
}

\section{Ronald Welch, University of Texas, Tyler}

Ron Welch is Professor and Head, Department of Civil Engineering at The University of Texas at Tyler. He is a registered Professional Engineer in Virginia. Until 2 Jan 2007, Ron was an Academy Professor at the United States Military Academy (USMA). Ron received a BS degree in Engineering Mechanics from the USMA in 1982 and MS and Ph.D. degrees in Civil Engineering from the University of Illinois at Urbana-Champaign in 1990 and 1999, respectively.

Ronald_Welch@uttyler.edu. 


\title{
Integrating Professional Topics and Engineering Constraints Across the Curriculum
}

\begin{abstract}
Most of us do not learn a skill the first time we try something. Same is true for engineering knowledge and attitudes. Therefore, developing engineering knowledge, skills, and attitudes cannot be relegated to single coverage within the curriculum. Topics must be introduced and wrestled with early in the curriculum, sustained through additional application during intermediate years, and engrained through integrated application during senior design. The concepts of globalization, public policy, and leadership and engineering constraints such as sustainability and ethics are introduced within the freshman engineering experience, cultivated during the sophomore and junior years, and analyzed and applied through senior year and senior design. It is through this integration across the curriculum that students develop a fuller understanding of these professional and design topics.
\end{abstract}

\section{Introduction}

Based on experience teaching the senior design course and as an ABET program evaluator (PEV), students applying engineering constraints for the first time in the curriculum during the senior design will not attain the level of performance and integration desired in ABET Outcome 3.c - "ability to design a system, component or process to meet needs within realistic constraints such as...". The same is true for professional topics such as demonstrating professional and ethical responsibility (3.f), engagement in life-long learning (3.i), function on a multi-disciplinary team (3.d), communicate effectively (3.g), and apply knowledge of contemporary issues (3.j). These topics are sometimes relegated to the senior seminar during the last semester before graduation if formally covered at all. If they are difficult to master and assess, then why are they continually addressed and sometimes demonstrated only once in the curriculum? PEV experience highlights that programs tend to not focus on what they do not understand.

ABET experience also highlights that many programs either have weak multi-discipline design experiences and/or do not consider more than economics when it comes to engineering constraints. During the early accreditation visits under EC2000, programs were expected to consider most if not all of the engineering constraints. Students wrestling with the constraints for the first time barely scratch the surface of understanding these constraints within their designs. Recently ABET $^{1}$ changed the wording of the outcome to "engineering constraints such as regulatory, economic, environmental, social, political, ethical, health and safety, constructability, and sustainability." Either it was recognized that not every design project would consider most of the engineering constraints or it might be impossible to get students to fully consider most of the engineering constraints. The new wording does require programs to consider more than one but not all engineering constraints within student design projects. Still it appears that many programs primarily focus on economics even at the senior level 
since it is the easiest constraint to start with and understand within even the first design courses like Mechanics of Materials (i.e., smallest member size). How does a program improve the student's use of engineering constraints?

The American Society of Civil Engineers (ASCE) has recognized the lack of certain knowledge and skills among recent graduates, while at the same time engineering programs are facing pressure to decrease credit hour requirements in undergraduate curriculums. ASCE formed a committee to study and develop a Civil Engineering Body of Knowledge $(\mathrm{BOK})^{2}$ to document the requisite knowledge, skills, and attitudes necessary for future civil engineers. Two key areas associated with the BOK was a definition of expected performance levels by these new engineers through Bloom's taxonomy ${ }^{3}$ as well as the adding of four new outcomes focused on additional professional topics and discipline depth. Very quickly it was determined by most programs and ASCE that the discipline depth could only occur at the Master's level. The additional professional skills above what even EC2000 requires reflect greater recognition of the importance of professional skills. Where are these supplementary professional topics to be just included in the current curriculum?

Another question that seems to be pertinent is how do students learn best? There is much research and discussion on the topic, but most educators generally agree that students learn best anything that they experience themselves as well as normally do repetitively. Many engineering educators have homework, design projects, and mid-term exams, and many times topics are tested again on a final exam. This process allows the student to first wrestle with the concept at their own pace in a homework assignment where they can collaborate with others before being asked to test their skills within a timed event such as an exam. Learning by doing is the primary basis behind the growth of projectbased learning (PBL) opportunities. ${ }^{4}$ Some programs have been completely sold on the concept to the point of desiring PBL for all learning activities within the program. ${ }^{5,6}$ These collaborative, team design experiences allow even deeper understanding through group work focused on a project. If this process is sound, then why are many professional topics and engineering constraints relegated to single activities, not being tested at all or students just being asked to know they exist?

The Department of Civil Engineering at The University of Texas at Tyler (UT Tyler) which is the newest program to be added to the College of Engineering and Computer Science began hiring faculty and admitting students in 2005. The students who made up the first graduating class in 2008 were actually admitted into the mechanical engineering program in 2004 with the anticipation of hiring the first CE faculty member. There were twelve students who declared themselves as future Civil Engineering (CE) students before the department officially existed. This placed these students on a path to graduate in May 2008. The timing could not have been better considering that the next scheduled ABET visit for UT Tyler was fall 2008 because of the previous accreditation visit in 2002 for the electrical and mechanical programs. A program cannot be considered for accreditation if they do not have at least one graduate at the time of the visit by ABET. Therefore, the program needed at least one of the twelve students to make it to graduation and demonstrate accomplishment of the program outcomes! 
With the primary growth of the program through freshmen and transfers, the full faculty team would not be in place until August 2008 which was just before the fall ABET visit. This last hire brought the faculty total to six with an average time of nine months at UT Tyler when the self-study was submitted. The faculty team had an average time of only four months at UT Tyler when the ABET record year began. The faculty are multidiscipline to provide overlap and coverage in multiple sub-disciplines of $\mathrm{CE}$ with a focus on professional practice: solid mechanics/geotechnical/structural, structural/materials, structural/water resources, mechanical/transportation, construction management/geotechnical, health services/environmental.

The issues and concerns mentioned above and the multi-disciplines of the faculty team were the driving forces behind these fundamental questions: can a new program rapidly improve the knowledge, skills and attitudes associated with professional topics demonstrated within the senior design experience? Does integration of professional topics across the curriculum improve student skill development? What is the best method to integrate and assess demonstration of professional skills? How and when do engineers consider each constraint within the design process and how and when should educators include them in courses and academic exercises?

\section{Professional Topics and Engineering Constraints}

The professional topics generally emanate from Outcomes 4, 6, 7, 8, and 9 of the UT Tyler CE Program Outcomes (PO) presented in Table 1 which are derived from ABET Outcomes (3.d), (3.f), (3.g), (3.h), (3.i), and (3.j) in Table 2 and the CE program criteria. PO 9 specifically incorporates the new undergraduate professional requirements located within the CE program criteria. The difficulty arises in how do students demonstrate or fully understand what these outcomes are asking when the demonstration is possibly left to a single event within the senior year. These professional outcomes have been referred to as "soft" outcomes by many when they were first presented as part of ABET EC2000 Criterion 3. Others have used the word "squishy" when considering how difficult it is to assess professional skills compared to the "hard" skills of engineers. "Soft" or "Squishy", the professional skills are not as easily assessed and many times require multiple assessment methods, multiple activities within the academic setting as well as activities like Engineers Without Borders or other service activities to be able to properly demonstrate accomplishment of the outcome. ${ }^{7}$ Another example of the difficulty is that students may properly assess a situation based on proper ethical reasoning, but there is no assurance that they will actually act ethically. Some define professional skills as how we perform in professional settings, but how do educators develop and assess such skills?

The consideration of engineering constraints listed in ABET Outcome 3.c (Table 2) as well as in UT Tyler PO 3 (Table 1) has not been much better since it is sometimes hard to define exactly how engineering constraints affect a design (i.e., social, political, ethical and sustainability). 
Table 1 UT Tyler Program Outcomes

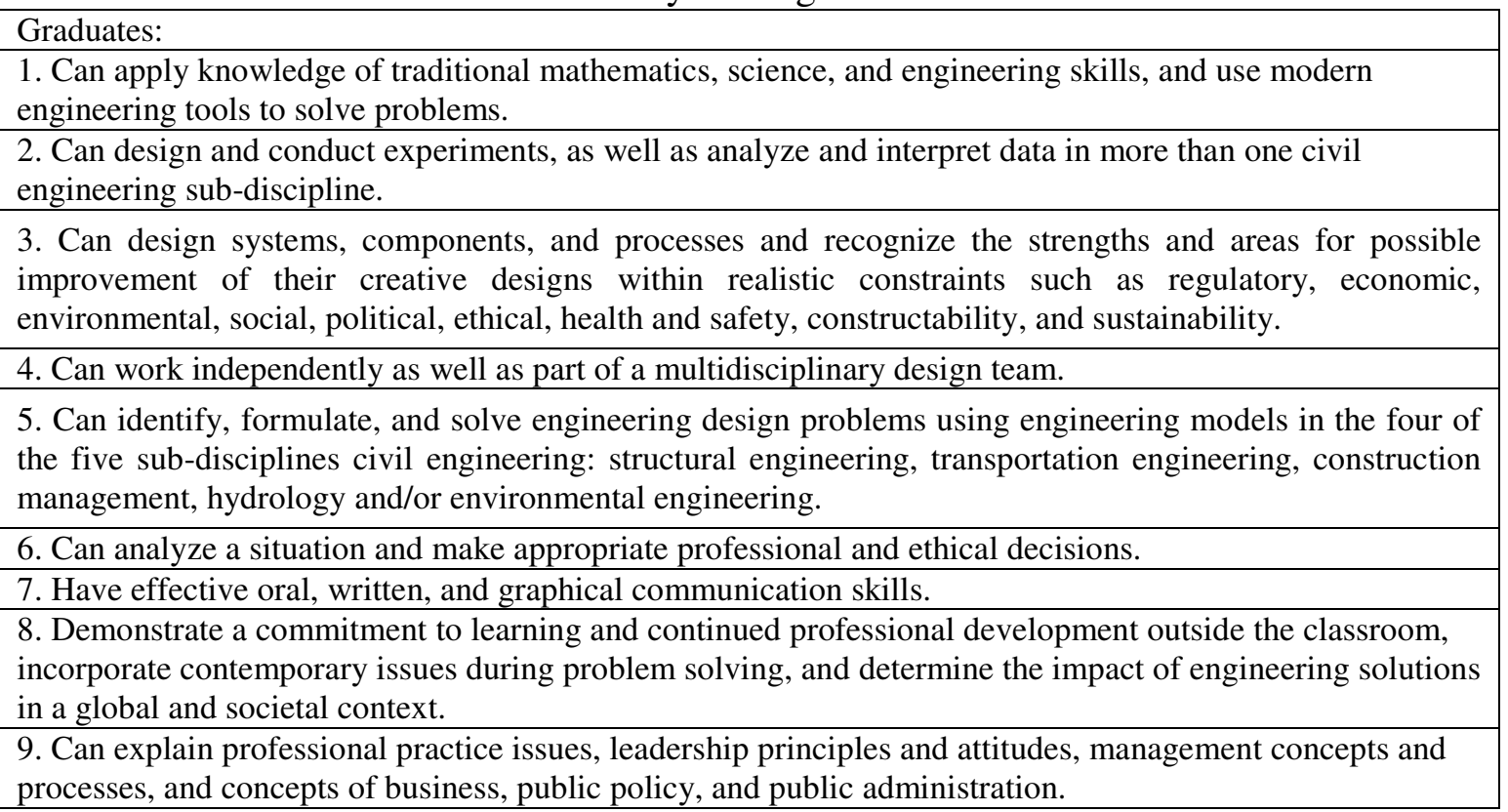

Table 2 ABET Criterion $3(\mathrm{a}-\mathrm{k})$

\begin{tabular}{|l|}
\hline Demonstration (incl. Process \& Measurements) that Graduates have: \\
\hline (a) ability to apply knowledge of math, engineering, and science \\
\hline (b) ability to design and conduct experiments \\
\hline (b) ability to analyze and interpret data \\
\hline (c) ability to design system, component or process to meet needs within realistic constraints such as \\
regulatory, economic, environmental, social, political, ethical, health and safety, constructability, and \\
sustainability. \\
\hline (d) ability to function on multi-disciplinary teams \\
\hline (e) ability to identify, formulate, and solve engineering problems \\
\hline (f) understanding of professional and ethical responsibility \\
\hline (g) ability to communicate effectively \\
\hline (h) broad education \\
\hline (i) recognition of need by an ability to engage in life-long learning \\
\hline (j) knowledge of contemporary issues \\
\hline (k) ability to use techniques, skills, and tools in engineering practice \\
\hline
\end{tabular}

\section{The Plan}

The CE program not only wanted to improve the demonstrated professional skills of the students in senior design, but also adequately demonstrate accomplishment of the professional outcomes in less than 1.5 years within its ABET self-study. The plan was simple: introduce the students to the professional topics and engineering constraints as early as possible with additional opportunities to wrestle with the concepts prior to applying them again in the senior design experience. The belief is that if students work with these professional topics and engineering constraints throughout the curriculum, then they are better suited to consider most if not all engineering constraints within a design process that also demonstrates accomplishment of professional outcomes. This appears to be a simple plan, but when added on top of the existing course content that is 
demonstrating "hard" skills, the task of developing and assessing the professional skill activity is not easy, especially when teaching a subject for the first time. All senior level courses to include the senior design were being taught for the first time with a junior faculty team during the ABET record year.

A unique opportunity to accelerate implementation of the plan presented itself when the new Chair of the Department of Civil Engineering who was to arrive in January 2007 was asked by the Dean to update the freshman engineering experience ENGR 1200 Engineering Methods ${ }^{9}$ to better engage and excite the students about engineering. Content for the course updates was derived from an engineering course at Princeton University developed by Professor David Billington (CEE102 - Engineering and the Modern World ${ }^{10}$ ) and the Summer Leaders Seminar ${ }^{11}$ for high school students at the United States Military Academy (USMA). The focus of the engineering course by Professor Billington is to provide a historical foundation as to how society arrived at the present modern engineering capabilities based on the past history of engineers and their engineering machines and how these machines and surrounding events affected the politics of public works, the economics of private enterprise, the rise of industry that reshaped regions, and the conflict between public environment and private profit. The course is offered at Princeton University to engineering students as a history/social science course and to non-engineering students as a technical course that requires a lab component. The underlying thought being that engineering students will have numerous laboratory experiences within their engineering academic career and being able to get a course on the history of modern engineering which counts toward a core requirement early in their career will provide them an unique insight into engineering. Additionally, the creative hands-on laboratory experiences and associated data collection will encourage some of the non-engineering students to consider switching to engineering! The presentation of engineering in the modern world within ENGR 1200 at UT Tyler also includes laboratory experiences for the freshmen engineering students. These laboratory experiences come from the Summer Leaders Seminar at USMA which allows academic programs to introduce their academic disciplines through a two and one-half hour hands on laboratories. The laboratory introductions for civil, mechanical, and electrical were modified and used as the main creative discipline recruiting/retention laboratory experiences within the modified ENGR 1200 experience.

The focus of ENGR 1200 is to provide a broad perspective on the history of modern engineering (taken from the Princeton University course), engineering skills needed throughout their engineering academic program (i.e., laboratory and design report writing), an introduction to engineering design without needing to know all of the details of design, and an insight into all of the engineering disciplines within the college (taken from the laboratory experiences within the Summer Leaders Seminars at USMA). However, it is the inclusion of engineering in the modern world and subsequent writing assignments that sets the stage for the defining and considering engineering constraints within the freshman engineering course. The two journals, two essays, and technical report are individual assignments, while the four laboratory reports and design report are group assignments. 
The first journal requires a full definition of the nine engineering constraints and the consideration of three to five constraints when discussing the impact of Telford and his bridges or Watt and his machines in England. The discussion leads to a deeper understanding as to how the design was impacted by or impacted the constraints. Telford actually conducted full scale tests as well as constructed many of his bridges in the foundry before moving to the construction site to ensure constructability and safety. Watt would not have been as successful without a politically connected partner in Boulton who was able to get a 25 year extension on his initial patent. The iron making process that made Telford's bridges economically possible caused huge environmental issues for England. The explosions of boilers on steam paddle boats eventually led to government regulation to provide for public safety. Telford's early success coupled with the rapidly growing field of civil engineering set the stage for the establishment of the first engineering society in England. With him as president the society began to influence future actions of engineers. The development of an engineering society naturally sparks discussion in the course as to the importance of professional societies and when and how do they get involved. Not all students properly define the constraints in their own words nor do they properly use when discussing the impact of an engineer and/or their device. However, the constant engagement and in-class discussions leads each student to build their understanding of each constraint. Of course these discussions further open the door for questions on professional topics such as ethics, public policy (regulatory agencies and pork barrel politics), the impact of engineering on society (social conditions of the working class during the industrial revolution), and life-long learning.

There are two journals, one essay and the technical report that require consideration of a number of engineering constraints when analyzing and arguing the impact that an engineer and their engineering feat had. Not only must the students consider all nine constraints within the technical report, but they must also discuss how contemporary issues were considered by their engineer of choice in their technical paper. The second essay is on the Mead Ethics contest topic and issued after a three hour laboratory discussion on what is ethics, the ASCE canons, and how it relates to what engineers do to include using the Milton F. Lunch ethic topics and case studies to spark discussion.

Leadership is thrust upon the freshmen through their laboratory teams. The team make-up is controlled by the faculty to ensure an equal spread of civil, mechanical, and electrical engineering students between teams. There are four graded laboratory experiences and a different student is appointed the leader for each laboratory. The civil engineering student(s) are appointed the leaders during the civil engineering laboratory experience and associated laboratory report preparation, and so on. The students construct a bridge using K'Nex that must support an arbitrary load. In the mechanical laboratory, the students build a Lego motor to lift an arbitrary weight. They build a strobe light on a breadboard as a team in the electrical lab before individually soldiering and building a strobe light on a pre-stamped breadboard that they get to keep. The computer science lab has the students modify the work done in the electrical lab and build a sensor that is capable of stopping the Lego motor when it has lifted a weight or moved a K'Nex structure a required distance. ${ }^{12}$ As team members become overloaded in other courses or become disinterested in the current engineering disciplinary focus, some leadership skills 
are developed, while some are severely tested. These same teams not only complete the design project (e.g., crane, lift bridge, elevator, or rotating bridge), but the team is required to analyze their performance as a team and the associated leadership each member displayed within the design report. The students are not left to develop their teams in a vacuum. They are guided through teaming using a two hour segment in the beginning of the semester on forming and leading teams. One interesting point of observation is that very few students ever miss the laboratory periods and most contribute equally on the team assignments even when they constantly are absent from the lecture period and have individual assignments that are very late. Perhaps the teaming exercises have an effect.

In each laboratory report and the design report the cost (economics) of K'Nex and Lego pieces is one of the constraints considered by the team by simply providing the students an arbitrary cost list for each piece of K'Nex and Lego they might use in the labs and design project. The economic constraint is pushed further with the inclusion of cost of construction labor in the design project through the timing of students building their device on competition day.

The final opportunity to demonstrate knowledge and skills is the senior design experience where the students consider engineering constraints as well as demonstrate professional skills as they complete their designs. The huge gap between freshman and senior year can be an issue if a program only covers professional skills within the freshman and senior years. However, many programs do not cover engineering constraints or professional skills in the freshman year. Since the faculty had no engrained practices before arrival at UT Tyler, a lengthy discussions focused on how learning is improved through repetition led the faculty to willingly agree to insert assessment of engineering constraints and professional skills in courses spread across the curriculum - teachers united to provide students similar requirements and development (constraints and professional skills) in courses each academic year. The ultimate goal was an activity and assessment for each constraint and professional skill in at least one sophomore course, one junior course, one senior course and the senior design experience. As a start, each course with any design content was requested to have the students consider as many constraints as feasible within the confines of the course.

An embedded indicator as defined by the CE program is a graded event or a portion of the graded event that directly demonstrates student accomplishment of a program outcome. ${ }^{13}$ Within the CE department, an embedded indicator package is defined as the assignment, the solution, a grading rubric used to grade the assignment or the portion of it demonstrating accomplishment of an outcome, an assessment of the students performance that includes how to adjust the course content to improve future performance or how to adjust the assignment to better assess the students understanding and sometimes both, and examples of student work: the best performance, the average performance, and the worst performance. These embedded indicators from each course are filed in a program outcome notebook. In the spring of 2007, the team discussed what the anticipated content of each course was and then assigned program outcomes to each course based on its perceived ability to have an assignment that would demonstrate a 
student's accomplishment of an outcome. The process was piloted in the spring of 2007 and the list was refined and assignments formalized. The goal during the ABET record year (2007-2008) was an average greater than 80 percent on each embedded indicator and any student who did not attain at least a 70 percent had to resubmit the assignment or portion of the assignment until they scored above 70 percent. The additional submittals did not alter the student's grade.

Coverage of the three new outcomes in BOK which are represented by program outcome 9 as well as demonstration of parts of Outcomes 6,7 , and 8 was to be provided by CENG 4341 Leadership, Public Policy, Business, and Asset Management. ${ }^{14}$ The course was added to the curriculum to ensure coverage of the topics in the title as well as other professional skills when the program was teaching its senior level courses for the first time during the ABET record year (2007-2008). Formal assignment of embedded indicators to courses based on perceived ability to demonstrate an outcome to include CENG 4341 provided the best odds at being BOK compliant while also passing the ABET visit. The result - the program received no deficiencies and no weaknesses. ${ }^{15}$ CENG 4341 synergistically assisted students in seeing the big design picture and the nuances of teamwork, leadership and management required in the two-semester senior design (CENG 4115/4315). Even though the CE program desires for public policy to be eventually covered in the introduction to environmental engineering, the program needed immediate coverage since CENG 3371 Introduction to Environmental Engineering is being taught for the first time during the Spring of 2009 and CENG 4371 Environmental Engineering Design (which had to cover introductory topics as well as design) was being taught for the first time during the ABET record year (spring 2008).

\section{Data collected}

During the 2007-2008 assessment cycle (the UT Tyler ABET record year), it was understood that any course that had a design experience was to incorporate as many engineering constraints as possible since most design experiences were listed as embedded indicators. Every assignment of the new course CENG 4341 Leadership, Public Policy, Business Practices, and Asset Management was designated as an embedded indicator (Table 3) to cover the new professional skills listed in the CE program criteria. Embedded indicators were assigned to each course to ensure adequate demonstration of outcomes (e.g., Table 4, example of the data collected for a portion of Outcome 6 and 9 for the ABET self-study). The embedded indicators were assessed and filed into a notebook for each outcome.

\section{Analysis of the data}

Even though there were a large number of design opportunities within the curriculum, the analysis of embedded indicators collected by outcome at the end of the 2007-2008 assessment cycle showed that there were lots of design embedded indicators, but few had more than economics being considered as part of the design. The ensuing discussion among the faculty after the exposed hard facts of the assessment depicted the strong desire to have students include more engineering constraints within design experiences, 
but in the heat of the semester teaching many courses for the first time faculty overlooked defining required consideration of appropriate engineering constraints. Additionally, some embedded indicator opportunities were missed completely. Further analysis of the design requirements and the developed grading rubrics highlighted the limited

Table 3 Embedded Indicators in CEG 4341

\begin{tabular}{|l|l|}
\hline Assignment & Outcome \\
\hline Paper 1 - define your leadership skills and attitudes. & $9 \mathrm{~b}$ - Leadership \\
\hline $\begin{array}{l}\text { Paper } 2 \text { - define your leadership goals while an intern using } \\
\text { appropriate leadership theories such as equity, expectancy, etc. }\end{array}$ & $9 \mathrm{~b}$ - Leadership \\
\hline $\begin{array}{l}\text { Paper 3 - define your leadership strategies for ensuring your } \\
\text { Capstone team is successful. }\end{array}$ & $9 \mathrm{~b}$ - Leadership \\
\hline $\begin{array}{l}\text { Exam 1, problem 1, define and explain leadership using } \\
\text { appropriate theories }\end{array}$ & $9 \mathrm{~b}$ - Leadership \\
\hline $\begin{array}{l}\text { Paper 4 - Define public policy while considering T. Boone } \\
\text { Pickens and West Texas Water rights }\end{array}$ & $9 \mathrm{e}-$ Public Policy \\
\hline $\begin{array}{l}\text { Paper 5 - define and provide the pros and cons for wetland public } \\
\text { policy }\end{array}$ & $9 \mathrm{e}-$ Public Policy \\
\hline $\begin{array}{l}\text { Presentation - 10 minute presentation on what can the do as part } \\
\text { of policy alternatives. }\end{array}$ & $9 \mathrm{e}-$ Public Policy \\
\hline $\begin{array}{l}\text { Exam 2, problem 1, define and explain public policy using } \\
\text { appropriate theories }\end{array}$ & $9 \mathrm{e}-$ Public Policy \\
\hline $\begin{array}{l}\text { Paper 6 - define a business plan through the eyes of an junior } \\
\text { engineer }\end{array}$ & $9 \mathrm{~d}-$ Business \\
\hline $\begin{array}{l}\text { Paper 7 - explain how you would improve the efficiency of asset } \\
\text { use within the company you worked for this past summer }\end{array}$ & $9 \mathrm{c}-$ Management \\
\hline Exam 3, Problem 1, define and explain business practices & $9 \mathrm{~d}-$ Business \\
\hline $\begin{array}{l}\text { Exam 3, Problem 4, Define and explain asset management though } \\
\text { lean six sigma and waste limitation }\end{array}$ & $9 \mathrm{c}-$ Management \\
\hline $\begin{array}{l}\text { Final Exam, Problem 1, explain leadership using theory and } \\
\text { examples }\end{array}$ & $9 \mathrm{~b}-$ Leadership \\
\hline $\begin{array}{l}\text { Final Exam, Problem 2, explain public policy using theory and } \\
\text { examples }\end{array}$ & $9 \mathrm{e}-$ Public Policy \\
\hline $\begin{array}{l}\text { Final Exam, Problem 3, explain business practices using theory } \\
\text { and examples }\end{array}$ & $9 \mathrm{~d}-$ Business \\
\hline $\begin{array}{l}\text { Final exam, Problem 4, explain asset management using theory } \\
\text { and examples }\end{array}$ & $9 \mathrm{c}-$ Management \\
\hline
\end{tabular}

requirements defining the need to consider engineering constraints at all. Even if an assignment had requirements to consider engineering constraints beyond economics, very few points were assigned allowing students to severely limit the time and thought placed on considering the impact of engineering constraints on their design. The coverage of engineering constraints was required in the senior design; however, the coverage was strong in a couple of areas, weak in some areas and not acceptable in others since it was really the first time this group of students had dealt with the constraints beyond economics in any focused effort. The seniors did not have the opportunity to experience 
coverage of engineering constraints in ENGR 1200 or other parts of the curriculum beyond the senior year where the coverage was limited to a single exercise in a course. However, the adequate coverage within the senior design of more than one constraint while trying to address each constraint was more than the PEV had seen in a number of programs over the years. No weakness or deficiency was noted by the PEV, but these areas were not as strongly demonstrated as the program would have liked.

Table 4 Assigned Embedded Indicators Completed

\begin{tabular}{|l|c|c|}
\hline \multicolumn{2}{|l|}{ Outcome 9c: Can explain management concepts and processes. } \\
\hline Direct Measures & Standard & $\begin{array}{c}2007-8 \\
\text { Performance }\end{array}$ \\
\hline $\begin{array}{l}\text { CENG 4339, Final Exam, Question \#27 } \\
\text { (cradle to grave management) }\end{array}$ & 80.0 & 100 \\
\hline $\begin{array}{l}\text { CENG 4341, Final Exam Question (Lean Six } \\
\text { Sigma, Eliminate waste) }\end{array}$ & 80.0 & 81.7 \\
\hline $\begin{array}{l}\text { Outcome 6a: Can analyze a situation and make appropriate } \\
\text { professional decisions. }\end{array}$ & Standard & $\begin{array}{c}2007-8 \\
\text { Performance }\end{array}$ \\
\hline $\begin{array}{l}\text { Direct Measures } \\
95.0\end{array}$ & 80.0 & 91.4 \\
\hline $\begin{array}{l}\text { CENG 3351, Project \#2 (One-Way Signal } \\
\text { Coordination/optimization to satisfy political } \\
\text { issues) }\end{array}$ & 80.0 & \\
\hline $\begin{array}{l}\text { CENG 4371, Environmental Design project } \\
\text { (design aerobic stabilization pond to balance } \\
\text { social, economic, political, environmental, and } \\
\text { public health issues) }\end{array}$ & & \\
\hline
\end{tabular}

The professional outcomes were generally covered through the embedded indicators within CENG 4341 Leadership, Public Policy, Business Practices, and Asset Management, the senior design sequence, and environmental engineering design. The professional outcomes focused on public policy, leadership, contemporary issues, and the impact of solutions were better addressed in the senior design spring semester because of the detailed coverage in CENG 4341 during the fall semester.

\section{Analysis of the steps taken, sustainable?}

The number of engineering constraints considered beyond economics was very few to include the senior design. This result occurred even though the faculty pledged to include the constraints at every opportunity to include senior courses. The coverage was weak in the senior design because the seniors had never considered the constraints before their senior year. Unless the individual engineering constraints are elevated to the same level of focus as program outcomes through embedded indicators (even though not all are evaluated properly), a simple desire does not equate to an actual requirement within an assignment. 
The students get the first exposure to engineering constraints and some professional topics in the ENGR 1200 course. The seniors are required to consider all engineering constraints as well as demonstrate accomplishment of many professional topics through acquired knowledge and skills. To improve the ability of the students within senior design, the faculty decided that embedded indicators for each engineering constraint needed to be added to the plate of embedded indicators for program outcomes.

Additionally, the analysis of the embedded indicators collected for professional outcomes 6,8 , and 9 were few and some were not good demonstrations of accomplishment of the outcome mostly due to the lack of faculty understanding of how these indicators should be demonstrated. Even though the analysis of outcome notebooks was completed by a two faculty member team who reviewed each outcome notebook of embedded indicators and made suggestions as to which embedded indicators to keep, which to drop and what additional activities and possible courses to provide embedded indicators, if they did not truly understand what the outcome meant, how can they truly make an evaluation of what is provided and make suggestions for improvement. The first step was an in-depth discussion during a department meeting of what each professional skill outcome means and how best to assess them. With a new understanding, the teams reviewed their work and determined that few of the profession skill outcomes truly were adequately demonstrated. Many professional outcomes only had two embedded indicators, and the FE does not really address them. Surveys are not the most ideal method of assessment, but are the best at determining whether graduates have the required professional skills (if the graduate understands what the outcome is asking). Unfortunately, the program has only one group of alumni who graduated less than a year ago and surveys traditionally have a low response rate. Therefore, the faculty team decided that there was a need for additional embedded indicators for professional skill program outcomes to fully demonstrate accomplishment of each outcome.

Once faculty are convinced that they need to assess each course assignment and exam to ensure that each graded requirement is accomplishing the desired result, the entire process is sustainable. If they are already assessing a course requirement, then the assessment of the assignment or the portion of the assignment to be used as an embedded indicator is just an extension of something they should already be doing. The faculty team must determine what course each academic year is the best suited to assess professional outcomes so that the students wrestle with each skill at least once each year. If the faculty team can ultimately boil down the number of embedded indicators to include engineering constraints to the irreducible minimum resulting in an equal spread of embedded indicators across each course, then the associated tasks are really a few additional minutes on top of the course tasks the faculty should already be doing. ${ }^{15}$

\section{Results}

The experiment was a success. The new program was able to adequately demonstrate knowledge, skills and attitudes associated with professional topics demonstrated within the senior design experience and other courses senior year for the current graduating 
group. However, the PEV could have found fault if we were a more mature program and presented the same data and results. The program has begun to more fully integrate professional topics across the curriculum and has already seen improvement in student skill development with this group of seniors as compared to the class that just graduated. The students are more comfortable with using their new skills and conducting deeper consideration of each constraint. The CE program has determined that the best method to integrate and assess demonstration of professional skills is to insert embedded indicators in appropriate courses, but only after in-depth discussion among the faculty as to what the professional outcome is asking demonstration of. Actual requirements to consider defined individual constraints and professional skills are needed within the sophomore and junior years, while the seniors must address the engineering constraints and professional skills within the 10, 35, and 100 percent submittals. However, the discussion and integration of the constraint effects must become more detailed and insightful as the design develops during each phase.

The review of embedded indicators collected (assessment will be completed in May 2009 when all embedded indicators have been filed) during only the fall portion of the 20082009 assessment cycle resulted in a thirty percent increase in embedded indicators for the professional topics and over 100 percent increase in examples considering engineering constraints (Table 5 vs. Table 4). The key has been identification of required embedded indicators for each course before the assessment cycle begins and for each faculty member to establish which assignments before the semester begins will include demonstration of program outcomes and engineering constraints, but especially professional outcomes like leadership, the impact of engineering solutions, consideration of contemporary issues, etc. Adequate thought is required to craft assignments that not only demonstrate course objectives that feed seamlessly into demonstrating the "hard" outcomes like design, modern tools, etc., but also demonstrate consideration of appropriate engineering constraints (e.g., Table 6) for each course as well as "professional" outcomes. 15

\section{Current actions}

The faculty team remains vigilante to push each other to stay focused on what embedded indicators are assigned to their course and that they have established and are living their plan as to which assignments include an embedded indicator established before the semester begins.

\section{Conclusions/Lessons Learned}

The faculty team must determine together the courses that should be able to provide an embedded indicator for each program outcome and engineering constraint. However, this is usually not enough; each professor must also develop a plan before the semester starts as to which assignments within the course will contain an embedded indicator or require the consideration of an engineering constraint. If the plan is not fully developed prior to the start of the semester, the normal day-to-day activities may (usually will) inhibit quality development of embedded indicators or prevent collection of embedded indicators 
that leaves some program outcomes without adequate demonstration of accomplishment. This is especially true for some of the professional outcomes which appear harder to demonstrate than other outcomes.

Table 5 Current Assigned Embedded Indicators

\begin{tabular}{|l|c|c|c|}
\hline \multicolumn{3}{|l|}{ Outcome 9c: Can explain management concepts and processes. } \\
\hline Direct Measures & Standard & $\begin{array}{l}2007-8 \\
\text { Performance }\end{array}$ & $\begin{array}{l}2008-9 \\
\text { Performance }\end{array}$ \\
\hline $\begin{array}{l}\text { CENG 4339, Final Exam, Question \#27 } \\
\text { (cradle to grave management) }\end{array}$ & 80.0 & 100 & \\
\hline $\begin{array}{l}\text { CENG 4341, Final Exam Question (Lean Six } \\
\text { Sigma, Eliminate waste) }\end{array}$ & 80.0 & 81.7 & \\
\hline CENG 4339 Project Delivery System & 80.0 & & \\
\hline CENG 4339 Project Scheduling Plan & 80.0 & & \\
\hline $\begin{array}{l}\text { CENG 4341, Exam 3, Question 3 Lean Six } \\
\text { sigma applied to a senario }\end{array}$ & 80.0 & & \\
\hline $\begin{array}{l}\text { CENG 4341 Paper Asset Management - apply } \\
\text { lean six sigma and waste reduction }\end{array}$ & 80.0 & & \\
\hline Outcome 6a: Can analyze a situation and make appropriate professional decisions. \\
\hline $\begin{array}{l}\text { Direct Measures } \\
\text { Standard }\end{array}$ & $2007-8$ \\
\hline $\begin{array}{l}\text { CENG 3351, Project \#2 (One-Way Signal } \\
\text { Coordination/optimization to satisfy political } \\
\text { issues) }\end{array}$ & 80.0 & 95.0 & \\
\hline $\begin{array}{l}\text { CENG 4371, Environmental Design project } \\
\text { (design aerobic stabilization pond to balance } \\
\text { social, economic, political, environmental, and } \\
\text { public health issues) }\end{array}$ & 80.0 & 91.4 & \\
\hline $\begin{array}{l}\text { CENG 3361, Hydro Project - location and size } \\
\text { based on social and political issues }\end{array}$ & 80.0 & & \\
\hline $\begin{array}{l}\text { CENG 4317, Steel Design Project - base load } \\
\text { resistance and factored design on public health } \\
\text { and safety }\end{array}$ & 80.0 & & \\
\hline $\begin{array}{l}\text { CENG 3371, Environmental Analysis project - } \\
\text { is the BOD an acceptable amount for a } \\
\text { discharge into a stream or a lake }\end{array}$ & 80.0 & & \\
\hline
\end{tabular}

Assessment of professional outcomes such as consideration of contemporary issues within problem solving, life-long learning, creativity within designs, and the societal impact of engineering solutions either will not take place or will be limited without an adequate understanding of what is required to demonstrate the outcome. Usually something that is not understood will not be implemented or implemented poorly. The faculty team must spend time wrestling with what each outcome means to them collectively and how best to demonstrate it. Leaving the task to each faculty member 
teaching a course will result in widely varying results. Using the definitions of professional process or awareness skills discussed within Shuman et. al. ${ }^{7}$ and the detailed discussion on each outcome in the appendices of $\mathrm{BOK}^{2}$ helped some faculty to come to grips as to what the outcome meant and how they can assess it using embedded indicators within their course. Many programs are turning to embedded indicators to accomplish the task of demonstrating an outcome. UT Tyler is using them to demonstrate consideration of engineering constraints. An insight by the UT Tyler faculty is that the consideration of engineering constraints can provide the needed focus to properly assess professional outcomes such as professional and ethical decision making, communication, engineering within a global and societal context, and knowledge of contemporary issues.

Table 6 Examples of Engineering Constraints Assigned to Courses

\begin{tabular}{|l|l|l|}
\hline Course & Engineering Constraint & Possible Topic \\
\hline CENG 3371 & SOCIAL & Brownfield \\
\hline CENG 3371 & POLITICAL/POLICY & $\begin{array}{l}\text { Regulations for } \\
\text { Environmental Quality }\end{array}$ \\
\hline CENG 3371 & SUSTAINABILITY & Recycling and reuse \\
\hline CENG 3371 & ENVIRONMENTAL & $\begin{array}{l}\text { Specific Areas of water, } \\
\text { air, and solid waste }\end{array}$ \\
\hline CENG 3371 & ETHICAL & Risk Assessment NIMBY \\
\hline CENG 3371 & PUBLIC HEALTH and SAFETY & $\begin{array}{l}\text { Community health and } \\
\text { Sanitation }\end{array}$ \\
\hline CENG 3371 & PUBLIC HEALTH and SAFETY & Radiation disposal \\
\hline CENG 2336 & POLITICAL/POLICY & Riparian squatters rights \\
\hline CENG 2336 & TECHNOLOGY & GPS/GIS \\
\hline CENG 3336 & MANUFACTURABILITY/CONSTRUCTABLITY & Foundations \\
\hline CENG 3336 & PUBLIC HEALTH and SAFETY & Slope failures \\
\hline CENG 3351 & SOCIAL & $\begin{array}{l}\text { Benefit of Intelligent } \\
\text { Transportation System } \\
\text { Deployment }\end{array}$ \\
\hline CENG 3351 & & $\begin{array}{l}\text { Cost of Intelligent } \\
\text { Transportation System } \\
\text { Deployment }\end{array}$ \\
\hline CENG 3351 & ECONOMIC & $\begin{array}{l}\text { Intelligent Transportation } \\
\text { System Deployment }\end{array}$ \\
\hline CENG 3361 & SUSTAINABILITY & $\begin{array}{l}\text { Tradeoff between flood } \\
\text { protection and \$ }\end{array}$ \\
\hline
\end{tabular}

Embedded indicators collected each year should be filed in a notebook for each outcome (and engineering constraint) and assessed by a faculty team to determine if the outcome (engineering constraint) is adequately demonstrated. The UT Tyler CE faculty defined each embedded indicator to have the following: assignment, solution, grading rubric, assessment, the best student work, the average student work and the worst student work. The assessment by the two person faculty team quickly observed that some of the examples provided did not adequately demonstrate accomplishment of the outcome or provided very limited linkage to the program outcome. In some cases, the entire faculty may need to once again discuss the definition and how best to demonstrate an outcome such as explanation of professional practice and how to assess students making professional decisions within current course content. 
Students cannot wait until senior design to consider engineering constraints for the first time. Otherwise many students will only provide limited coverage based on their usual lack of full understanding of what the engineering constraint means and how to best apply it. The students must have the engineering constraints introduced early in the curriculum and required to address each on numerous occasions before being asked to consider them within the senior design experience. The same is true for all of the professional topics. Bottom line: most faculty have never been asked to demonstrate professional outcomes when they were in school, and asking them now to develop activities to have their students demonstrate these professional skills will take time. It is like asking a student to define proper teaching pedagogy. They normally cannot, but they can point out a good teacher when they experience one. With time reflecting on what a good teacher does, the student can adequately define proper teaching pedagogy. Faculty will need to try to demonstrate professional outcomes in class and have the students wrestle with the concept and reflect over multiple opportunities to address each professional outcome before the students will be comfortable demonstrating professional outcomes and considering engineering constraints. The best approach is introduction of each in the freshman engineering experience, ${ }^{16}$ an opportunity to exercise their understanding of each during both the sophomore and junior years in an appropriate course, and then application of their elevated skills within the senior design.

\section{References}

${ }^{1}$ ABET general criteria. http://www.abet.org/forms.shtml\#For_Engineering_Programs_Only Accessed 30 Jan 2009.

${ }^{2}$ ASCE Body of Knowledge Committee. 2004. Civil Engineering Body of Knowledge for the $21^{\text {st }}$ Century: Preparing the Civil Engineer for the Future, Reston, VA, January. (http://www.asce.org/raisethebar ). Accessed 30 Jan 2009.

${ }^{3}$ ASCE Body of Knowledge Achievement Committee. 2005. Levels of Achievement Applicable to the Body of Knowledge, Reston, VA, September. http://www.asce.org/pdf/LevelsAchievement110205.pdf Assessed 30 Jan 2009.

${ }^{4}$ Thomas, J.W., “A review of research on project-based learning,” Research supported by the Autodesk Foundation, Mar 2000.

5Jones, B.F., Rasmussen, C.M., and Moffitt, M.C. "Real-life problem solving: A collaborative approach to interdisciplinary learning," Washington, DC: American Psychological Association, 1997.

${ }^{6}$ Engineering Engineering Education - A Catalyst Workshop for Change, Bucknell University and the National Science Foundation, NSF Grant 99-72758. 2000-2005. 
${ }^{7}$ Shuman, L.J., Besterfield-Sacre, M., McGourty, J., “The ABET "Professional Skills" Can they taught? Can they be assessed?" Journal of Engineering Education, 94(1), 41-55.

${ }^{8}$ Welch, R.W., Estes, A.C., and Winget, D., “Assessment of Squishier Outcomes: OpenEnded Problem Solving Through Client-Based Projects," 2005 ABET Annual Meeting, San Diego, CA, 27-28 October 2005.

${ }^{9}$ http://ce.uttyler.edu/Documents/ENGR1200ABETsyl2008Jun.pdf Accessed 30 Jan 2009.

${ }^{10}$ http://www.princeton.edu/cee/undergraduate/courses/course_details.xml?courseid=008 721\&term=1092 Accessed 30 Jan 2009.

${ }^{11}$ http://admissions.usma.edu/moreinfo/SLSCourseDescriptions2008.pdf, Seminar O. Accessed 30 Jan 2009.

${ }^{12}$ Welch, R.W, "Engaging Freshman Experience - Key to Retention?" Proceedings of the American Society of Engineering Education Annual Conference, Austin, TX, 14-17 June, 2009.

${ }^{13}$ Meyer, K.F., Estes, A.C., Welch, R.W., Winget, D., "Program Assessment the Easy Way: Using Embedded Indicators to Assess Program Outcomes," Proceedings of the American Society for Engineering Education Annual Conference, Chicago, IL, 19-22 June, 2006.

${ }^{14}$ http://ce.uttyler.edu/Documents/CENG4341ABETsyl2008Jun.pdf Accessed 30 Jan 2009.

${ }^{15}$ Welch, R.W, "Surviving ABET Under the New Criteria - From the Eyes of New Chair in a New CE Department," Proceedings of the American Society of Engineering Education Annual Conference, Austin, TX, 14-17 June, 2009.

${ }^{16}$ Practicing Engineering in a Freshman Introductory Course, IEEE Transactions on Education, Vol. 49, No. 1, February 2006 